\title{
Retroviral vectors
}

\author{
K M Kurian, C J Watson, A H Wyllie
}

Sir Alistair Currie CRC Laboratories, Molecular Medicine Centre, Western General Hospital, Crewe Road, Edinburgh EH4 2XU, UK

K M Kurian

C J Watson

A H Wyllie

Correspondence to: Dr Kurian

Accepted for publication 11 April 2000

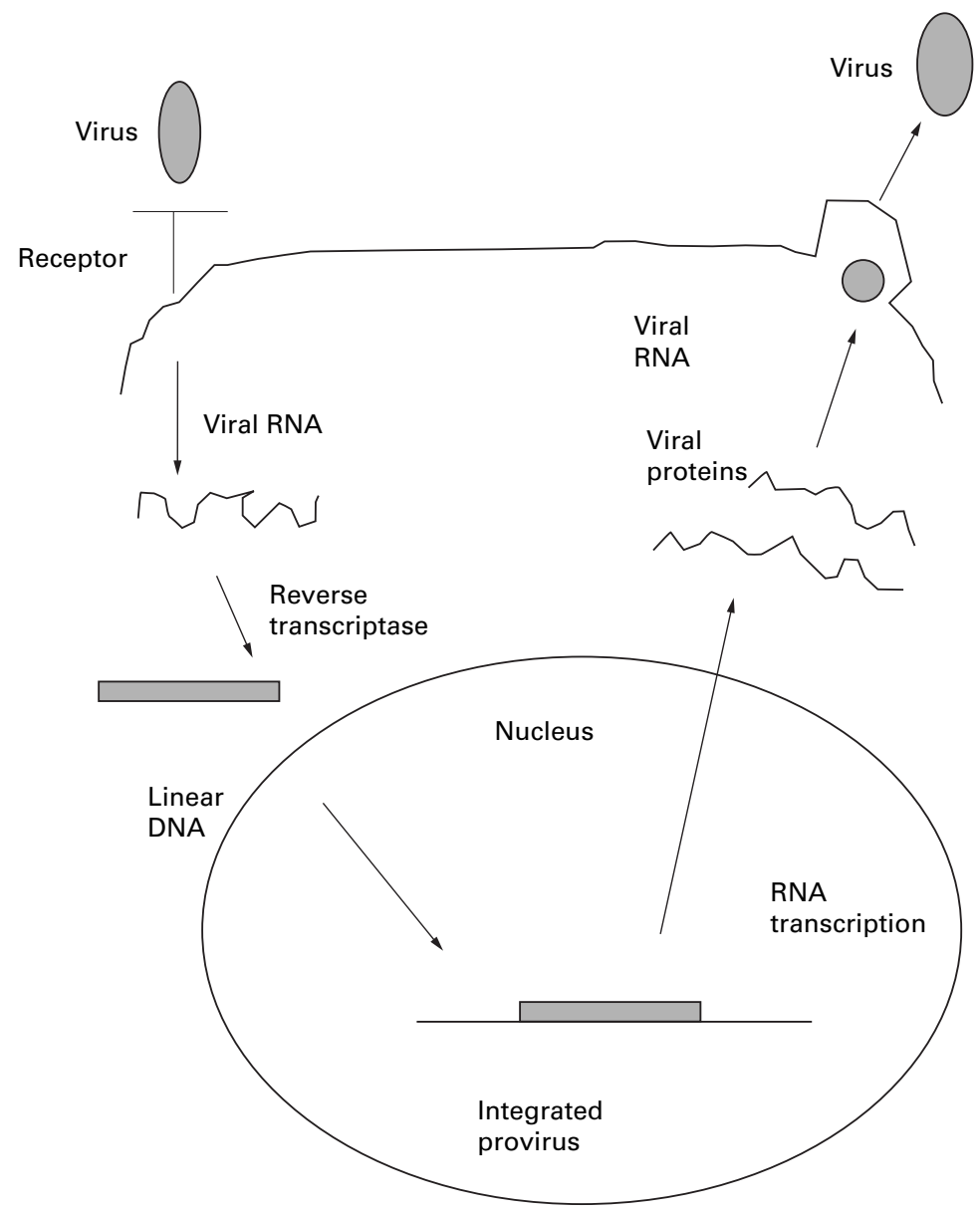

Figure 1 The murine leukaemia retrovirus life cycle.

Keywords: retrovirus; provirus; reverse transcriptase; murine leukaemia virus, ecotrophic

Viral techniques of gene transfer harness the method of entry and integration with the host genome used by the wild-type organism. They

\begin{abstract}
Traditionally, the retrovirus is regarded as an enemy to be overcome. However, for the past two decades retroviruses have been harnessed as vehicles for transferring genes into eukaryotic cells, a process known as transduction. During this time, the technology has moved from being a scientific laboratory tool to a potential clinical molecular medicine to be used in gene therapy. This review explains the strategy for harnessing the retrovirus life cycle, the scientific research and clinical applications of this methodology, and its limitations, as well as possible future developments.

(f Clin Pathol: Mol Pathol 2000;53:173-176)
\end{abstract} that is manipulated to form retroviral vectors for gene transfer. The provirus then undergoes transcription and translation with the rest of the genome, resulting in the assembly of new viral particles that bud off the surface of the target cell to infect others cells. ${ }^{5}$

\section{Vector technology}

A retroviral vector consists of proviral sequences that can accommodate the gene of interest, to allow incorporation of both into the target cells. The vector also contains viral and cellular gene promoters, such as the CMV promoter, to enhance expression of the gene of interest in the target cells. The most important advance in vector technology has been use of the packaging cell. ${ }^{6}$

Packaging cells are typically fibroblast derivatives that contain sequences of independently coding DNA sequences, known as DNA plasmids, expressing viral gene products such as gag and pol. When the retroviral vector with the gene of interest is introduced into the packaging cells by non-viral transfection techniques, virions containing the vector genome are produced, which bud off into the culture medium (fig 2). These are then allowed to infect and stably integrate with the genome of dividing target cells. The retroviral vector is not able to replicate further because it does not encode the viral structural proteins, which had been provided by the packaging cell. Detailed reviews on packaging cell and vector design are available elsewhere. ${ }^{6-9}$ 


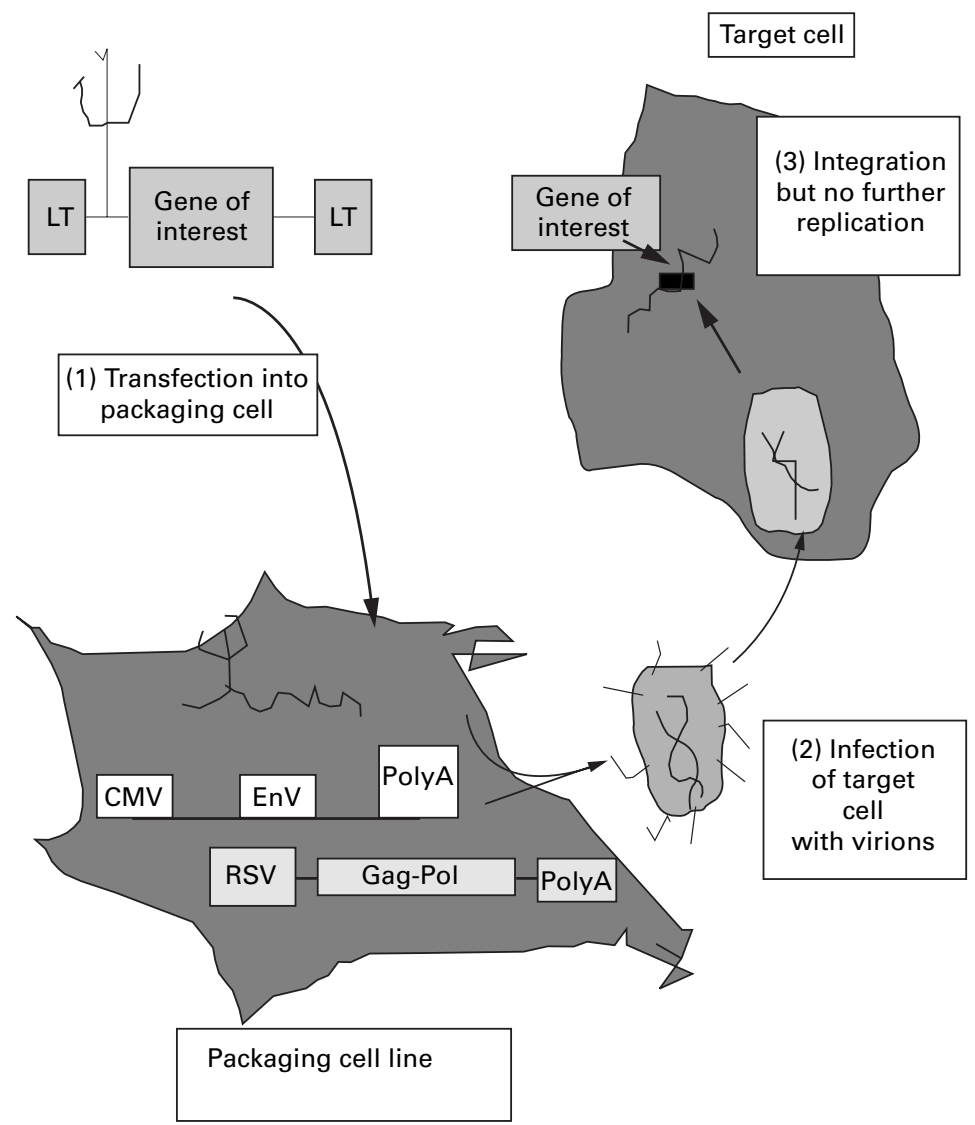

Figure 2 The production of retrovirus and infection of target cells.

Scientific applications (fig 3)

The retroviral approach has been used to express genes in embryonic tissues to allow the investigation of their developmental function. These experiments, which have been carried out extensively in avian species, involve injecting viral vectors into embryos and assessing their development. An alternative approach is to introduce a biologically neutral gene as a marker of the descendants of target cells in cell lineage studies ${ }^{10}$; for instance, the marker gene may be a certain colour, such as blue Lac Z. These studies use small numbers of virions so that individual cells are infected and the subsequent clone of cells can be followed.

Moreover, retroviruses can be used to manipulate the germline to express genes in

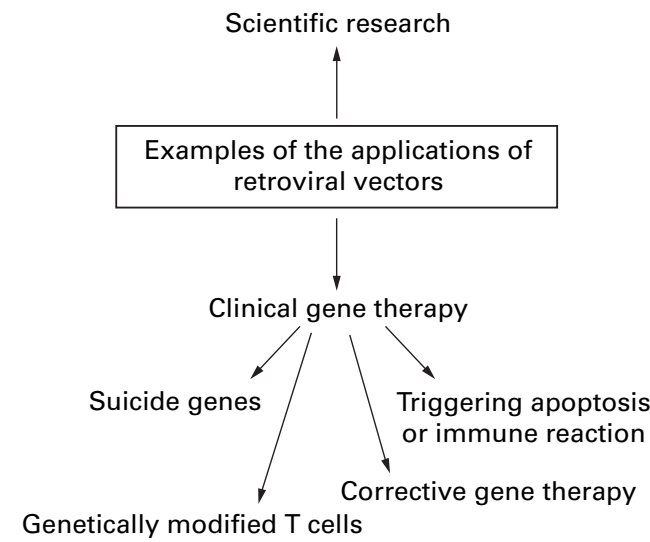

Figure 3 Examples of the applications of retroviral vectors. transgenic animals. This is achieved by infecting pre-implantation embryos or embryonic stem cells in culture. Unfortunately, this method has a poor success rate as a result of the host recognising foreign DNA and inactivating it by methylation, particularly in the case of pre-implantation embryos. ${ }^{11}$ An alternative approach involves inserting a marker gene to enable researchers to follow animals with mutant phenotypes visually, in a similar way to the cell lineage studies. ${ }^{12}$

Identification of the integration sites of the retrovirus enhances our knowledge of the replicative strategies of the retrovirus, as well as potentially isolating oncogenes. To identify an integration site, a selectable antibiotic resistance marker is inserted into the virus, which is allowed to infect target cells. When target cells are administered a particular antibiotic, only those cells containing the marker survive. These cells containing viral integration sites are grown and their DNA analysed using restriction enzymes to identify the relevant sequences at which the virus has integrated with the host DNA. ${ }^{3}$

\section{Clinical applications (fig 3)}

Retroviral vector technology is the method used most commonly for gene transfer in gene therapy. ${ }^{13}$ However, although several clinical trials are under way, success has been limited because of problems transducing sufficient numbers of target cells. There are two general approaches: namely, in vivo gene therapy, in which genes are delivered directly to target cells; and the more usual ex vivo therapy, in which the target cells are genetically modified outside the body and then transplanted. Retroviral vectors have been used to introduce a drug susceptibility or "suicide" gene, such as herpes simplex thymidine kinase (TK), to target cells. ${ }^{14}$ When the patient is treated with a particular drug, such as gancyclovir, the target cells containing TK are killed selectively. The suicide gene approach has been used with some success for the treatment of recurrent malignancy. For example, when $T$ cells, which have been previously harvested, are administered to patients with melanoma on the development of a recurrence, they are effective in destroying malignant cells. ${ }^{15}$ Unfortunately, the T cells can go on to damage normal tissue. Therefore, the harvested $\mathrm{T}$ cells are retrovirally transduced with a suicide gene, so that they can be removed after they have eliminated the recurrent tumour.

A more corrective approach has been used to restore apoptotic pathways in tumour cells by introducing apoptosis related genes, such as p53 and bcl-xs, ${ }^{16}$ via retroviral vectors. However, experimentally both p53 and bcl-xs were unable to induce apoptosis in certain tumours, and it may be that a more complex set of signals is necessary to trigger this pathway. At present, the experimental focus has shifted to Fas ligand stimulated apoptosis. One success with the corrective approach has been in the treatment of the human genetic disease adenosine deaminase (ADA) deficiency, which results in children having severe combined 
immunodeficiency. ${ }^{17}{ }^{18}$ The biochemical defect is a build up of deoxyadenosine - an ADA substrate-which is converted to a toxic compound that disables T cells. Patients can be treated by retroviral mediated gene therapy to reintroduce $\mathrm{T}$ cells corrected for the defect, as well as by enzyme replacement. Although this treatment appears to overcome the disease, it has been difficult to separate the effectiveness of the gene therapy from the enzyme treatment.

Retroviral vectors have also been used in alternative efforts to enhance the body's own immune response to tumours; this treatment involves reinjecting tumour cells that have been UV irradiated, genetically manipulated, or admixed with non-specific adjuvants. Combinations of these strategies are under way, but to date success has been limited. ${ }^{19}$

\section{Limitations}

SAFETY

The main potential hazard of this technology is the production of replication competent virus, which can infect humans. The choice of retrovirus can limit the possibility of cross infection in the laboratory set up. For example, ecotrophic viral species that infect murine cells only are less hazardous compared with amphotrophic viruses, which have a broad host range including humans. ${ }^{5}$ However, in clinical applications, infection of human cells is desirable, and there has been no record of inadvertent infection or malignancy during the equivalent of 30 patient years experience of gene therapy. However, the potential hazard remains real. In experiments designed to test the dangers of retroviruses, which exposed 10 immunocompromised monkeys to replication competent vectors, three experimental monkeys contracted malignant $\mathrm{T}$ cell lymphoma. ${ }^{2}$

Furthermore, even with replication defective vectors, it is possible that integration of the retroviral vector occurs within an important locus in the target cell. Moreover, the integration could potentially inactivate a tumour suppressor gene or activate an oncogene, thus promoting tumorigenesis of the target cell.

In addition, the viral reverse transcriptase presents a potential hazard because it is characteristically highly error prone. ${ }^{1}$ For example, in corrective gene therapy experiments, which aim to transduce target cells with wild-type p53, a proportion of target cells might receive mutated $\mathrm{p} 53$ because of errors of reverse transcription.

\section{RETROVIRAL TITRE}

Apart from safety considerations, a major limitation of retroviral vectors is the low titre produced by the packaging cells. At present, they generate virus at approximately $10^{6}$ to $10^{7}$ infectious particles $/ \mathrm{ml}$ of tissue culture supernatant. ${ }^{6}$ Several technical strategies are under way to improve this "real" titre. However, the "effective" titre is even lower owing to several factors. First, most murine retroviruses on which gene therapy vectors are based are rapidly inactivated by human complement. At present, viruses with modified envelopes to resist complement inactivation are being developed. ${ }^{14}$ Another main drawback is that murine retroviral vectors infect actively dividing cells only. A future possibility is that the lentiviruses (for example, human immunodeficiency virus (HIV)) might overcome the inability of retroviral vectors to infect quiescent cells. The ability of HIV to infect non-dividing cells might result in part from a nuclear transport signal that allows transport of the provirus to the nucleus in the absence of mitosis. ${ }^{20}$ It is not clear at present whether incorporation of these sequences into traditional retroviral vectors will allow similar division independent infection to occur.

\section{GENE EXPRESSION}

Although the retrovirus stably integrates into the target cell genome, it is clear that the choice of promoter chosen to drive expression of the therapeutic gene is crucial. Although the promoter drives high levels of gene expression in vitro, there is often a lack of gene expression in vivo because of the methylation of viral promoters. ${ }^{19}$ At present, vectors that have cellular promoters are being developed; these might be less susceptible to transcriptional shutdown than viral promoters. In the future, self inactivating vectors, which remove all viral promoters after integration with the target cell, leaving the cellular promoter alone, might combat this problem.

\section{Future developments}

The future development of retroviral technology to overcome these limitations might hinge on the targeting of vectors.

Two main possibilities include cell surface targeting or transcriptional targeting. In principle, cell surface targeting should be the easier to achieve because of the well defined packaging system and current detailed knowledge of retroviral receptor structure. ${ }^{21}$ Several groups have shown that the trophism of retroviral vectors can be altered by the incorporation of hybrid proteins into the envelope of the virus; however, this is not yet advanced enough to produce high titre stocks. ${ }^{22}$ Transcriptional targeting could be achieved by incorporating transcriptional control elements that restrict expression of the inserted gene in target cells. Although several such retroviral vectors have been described, in many cases different interacting promoter elements have resulted in a partial loss of cell type specific gene expression. $^{6}$

In conclusion, far from being a foe, retroviruses have been harnessed so that they are used routinely for gene transfer in the laboratory setting and in clinical trials of gene therapy. The mains drawbacks at present centre round potential safety, retroviral titre, and gene expression. In the future, it might be that powerful hybrid delivery systems that utilise the desirable properties of different vectors can be synthesised according to individual laboratory and clinical requirements.

$\mathrm{K}$ Kurian is an Edinburgh University medical faculty research fellow. This work was kindly supported by the Cunningham Trust. 
1 Stoker AW. Retroviral vectors. In: Davison AJ, Elliot RM, eds. Molecular virology: a practical approach. Oxford: IRI Press, 1993:171-97.

2 Vile RG, Russell SJ. Retroviruses as vectors. $\mathrm{Br}$ Med Bull 1995;51:12-30.

3 Brown PO. Integration of retroviral DNA. Curr Top Microbiol Immunol 1990;157:19.

4 Weiss RA, Tailor CS. Retrovirus receptors. Cell 1995;82: 531-3.

5 Weiss RA. Retroviruses. Nature 1998;392:561.

6 Markowitz D, Hesdorffer C, Ward M, et al. Retroviral gene transfer using safe and efficient packaging cell lines. Ann $N$ $Y$ Acad Sci 1990;612:407-14.

7 Armentano D, Yu S-F, Kantoff PW, et al. Effect of internal viral sequences on the utility of retroviral vectors. I Viro 1987;61:1647.

8 Kinsella TM, Nolan GP. Episomal vectors rapidly and stably produce high-titer recombinant retrovirus. Hum Gene Ther 1996;7:1405-13.

9 Iida A, Chen, ST, Fiedmann T, et al. Inducible gene expression by retrovirus-mediated transfer of a modified sion by retrovirus-mediated transfer of a modi

10 Cepko CL, Ryder EF, Austin CP, et al. Lineage analysis Cepko CL, Ryder EF, Austin CP, et al. Lineage analysis
using retroviral vectors. In: Wasserman PM, DePamphilis using retroviral vectors. In: Wasserman PM,

11 Jahner D, Stuhlmann H, Stewaet CL, et al. De novo methylation and expression of retroviral genomes during mouse embryogenesis. Nature 1982;298:623-5.
12 Onishi M, Kinoshita S, Morikawa Y, et al. Applications of retrovirus-mediated expression cloning. Exp Hematol 1996; retrovirus

13 Russell SJ. Gene therapy. BMF 1997;315:1289-92.

14 Takeuchi Y, Cosset FL, Lachmann PJ, et al. Type C retrovirus inactivation by human complement is determined by both the viral genome and the producer cell. F Virol 1994; 68:8001-7.

15 Rosenberg SA, Aebersold P, Cornetta K, et al. Gene transfer into humans: immunotherapy of patients with advanced melanoma using tumor infiltrating lymphocytes modified by retroviral gene transduction. $N$ Engl f Med 1990;323: 570-8.

16 Nielsen LL, Maneval DC. p53 tumor suppressor gene therapy for cancer. Cancer Gene Ther 1998;5:52-63.

17 Blaese RM. T-lymphocyte-directed gene therapy for ADASCID: initial trial results after 4 years. Science 1995;270: 475-80.

18 Cohen P. The greater good. New Scientist 1998;2155:5.

19 Friedmann T. Overcoming the obstacles to gene therapy. $S c i$ Am 1997;276:80-5.

20 Lewis PF, Emerman M. Passage through mitosis is required for oncoretroviruses but not for the human immunodeficiency virus. $\mathcal{F}$ Virol $1993 ; 68.510-16$.

21 Miller N, Vile RG. Targeted vectors for gene therapy. FASEB F 1995;9:190-9.

22 Salmons B, Gunzburg WH. Targeting of retroviral vectors for gene therapy. Hum Gene Ther 1993;4:129-41.

\section{Fournal of Clinical Pathology - http://www.molpath.com}

Visitors to the world wide web can now access the fournal of Clinical Pathology either through the BMJ Publishing Group's home page (http://www.bmjpg.com) or directly by using its individual URL (http://www.molpath.com). There they will find the following:

- Current contents list for the journal

- Contents lists of previous issues

- Members of the editorial board

- Information for subscribers

- Instructions for authors

- Details of reprint services.

A hotlink gives access to:

- BMJ Publishing Group home page

- British Medical Association web site

- Online books catalogue

- BMJ Publishing Group books.

The web site is at a preliminary stage and there are plans to develop it into a more sophisticated site. Suggestions from visitors about features they would like to see are welcomed. They can be left via the opening page of the BMJ Publishing Group site or, alternatively, via the journal page, through "about this site". 